\title{
Case study: flood impact reduction
}

\author{
Y. Peddemors \& B. Willemse \\ Provincie Zeeland, The Netherlands
}

\begin{abstract}
Multi-level safety (MLS) is part of the National Waterplan [1], the official government plan for national water policy in the Netherlands. MLS pursues sustainable flood risk management in 2016.

The MLS-approach consists of three layers. The first layer concerns prevention: to minimize the occurrence of floods. The second layer aims at flood impact reduction. The third layer deals with a better preparation for the occurrence of a flood. The developed method is an area-specific risk approach that looks at an optimal combination of measures from all three layers. In this paper we concentrate on the second layer, the mandate of the Dutch provinces.

Over the centuries floods have invaded the Dutch delta area. Since the year 1200 these floods and subsequent land reclamations have formed the province of Zeeland. Many former sea dikes became inland dikes, so called "sleeper dikes". And while they have lost their original function as primary flood protection, they remain as a network of over a thousand miles of elevated tracks that can serve to reduce the impact of a flood. This makes Zeeland a region particularly suitable for MLS.

To explore the (im)possibilities of these sleeper dikes we have to broaden our focus. Due to the vast anthropogenic elements in today's world, it is nearly impossible to neglect any field of activity. Inspired by Carl Steinitz we have applied the method of changing geography by Geodesign to the development of MLS. The objective is to achieve better spatial planning and to improve the decision-making process.
\end{abstract}

Keywords: multi-level safety, flood impact reduction, Geodesign, spatial planning. 


\section{Introduction}

In 1953 a mayor storm caused enormous floods in England, Belgium and the Netherlands. In the Dutch delta area 1836 people lost their lives and 500,000 acres of the inhabited area were invaded by the North Sea [2]. The flood of 1953 led to faster decision-making and more decisive flood protection measures. It was the direct occasion of the implementation of the Deltaworks [3]. Nowadays, preventive measures for large-scale maintenance and improvement of dikes, dunes and beaches are thoroughly embedded in the Dutch legislation. In the year 2016 reinforcement of all the dikes along the Zeeland estuaries of the Oosterschelde and Westerschelde will be completed. Meanwhile the EU Flood Directive [4] requires Member States to identify the possible impact of future floods. The province of Zeeland has calculated their future flood impacts, conform nation-wide established (hydraulic) conditions, formulas, assumptions and manuals. The results of these flood impact calculations are open to the public since December 2013. The accompanying flood risk management plans should be ready before 2016 .

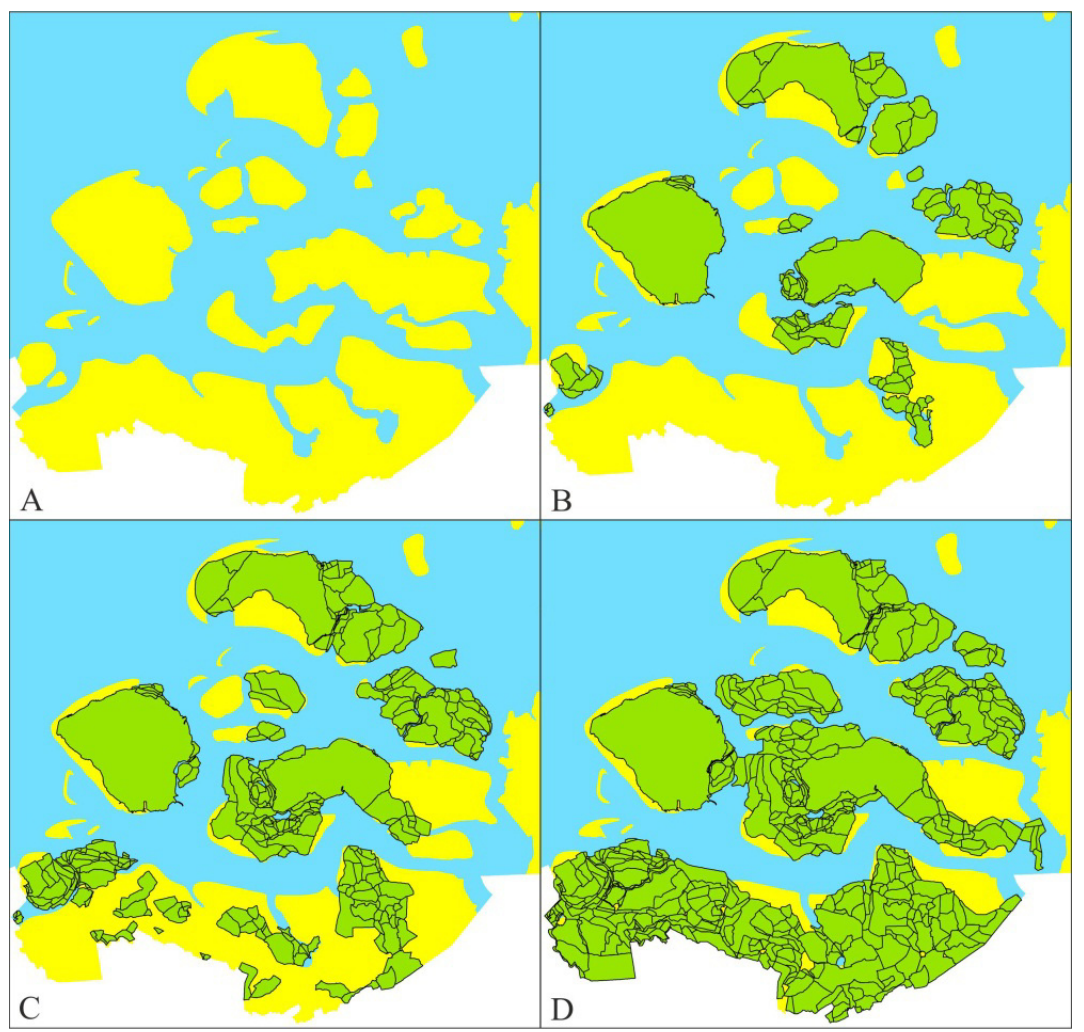

Figure 1: $\mathrm{A}-1250 ; \mathrm{B}-1400 ; \mathrm{C}-1600 ; \mathrm{D}-1952$. 
The province of Zeeland is situated in the Dutch delta area. Due to areaspecific geographical features Zeeland is different from the rest of the Netherlands and Northwest Europe. Since the year 1200, mayor floods and subsequent land reclamations have formed this delta area. Many former sea dikes became inland dikes, so called "sleeper dikes", fig. 1.

One of the nation-wide established assumptions is: sleeper dikes have enough height and stability to limit the impact of floods. This assumption is to compare flood impact calculations in an unambiguous way across provincial borders. However, we do not know whether this assumption is correct. More importantly, nowhere in the Netherlands this assumption has so much influence on the outcome of flood impact calculations as in a geographically unique landscape as the Zeeland estuary.

In 2016, the province of Zeeland expects to finish its research on the predictability of future flood impacts in relation to sleeper dikes. Prior to this research we have examined several strategies in a case study "flood impact reduction" involving multi-level safety (MLS) [5] and Geodesign [6].

\section{Flood impact reduction}

In order to achieve flood impact reduction, the province of Zeeland started to identify promising locations, elaborate integrated provincial policy and visualize spatial developments. Taking into account all sleeper dikes, this means we have to focus on area-specific research and aim at the predictability of future flood impacts.

\subsection{Multi-level safety}

Multi-level safety (MLS) is part of the National Waterplan, the official government plan for national water policy in the Netherlands. MLS pursues sustainable flood risk management in 2016.

The MLS-approach consists of three layers. The first layer concerns prevention: to minimize the occurrence of floods. The second layer aims at flood impact reduction. The third layer deals with a better preparation for the occurrence of a flood. The developed method is an area-specific risk approach that looks at an optimal combination of measures from all three layers. In this paper we concentrate on the second layer, where the Dutch provinces are primarily responsible.

\subsubsection{Responsibilities of the province of Zeeland}

The main assignment of the province of Zeeland is to develop sustainable spatial planning. This covers the second layer of MLS as well. Hence the Dutch government made the provinces responsible for calculating flood impacts.

The second layer in MLS-approach also requires building customized and protecting critical infrastructure. This infrastructure supports the third layer of MLS and creates solid evacuation routes and place of safety. 


\subsubsection{Solutions}

There are several potential solutions. The main types are related to engineering design, process management and strategy. One thing is for sure, the focus should not be on short-term planning. In the search for MLS solutions in a highly floodprone area, each solution should have long-term vision.

\subsubsection{Mission (im)possible?}

The current flood impact calculations show that $90 \%$ of Zeeland will flood if the primary dikes and dunes do not withstand a storm surge. So it will be quite a difficult task to identify promising locations for sustainable spatial planning. Especially considering the challenging consequence of discouraging people from living and working in flood-prone areas.

This causes the need to enlarge flood awareness in the province of Zeeland to create a wider support among citizens, businesses and decision-makers, right from the start.

\subsection{Sleeper dikes}

Sleeper dikes are inland dikes that at some point in earlier times separated land and sea. Over the centuries they have lost their original function as primary flood protection. In the Zeeland estuary they remain as a network of over a thousand miles of elevated tracks that can serve to reduce the impact of a flood, fig. 1.

The current flood impact calculations show that sleeper dikes have an enormous influence on the theoretical outcome of each breach in the present primary flood defences.

\subsubsection{Enforcement}

Maintaining strong primary flood defences, part of the first layer of MLS, is embedded in the Dutch National Waterplan. However, "waking up" sleeper dikes and reinforce some as secondary flood defences, still is under debate. Yes, sleeper dikes affect flood impacts, but can they contribute cost effectively to flood impact reduction as secondary flood defences?

Recently the province of Zeeland has identified a network of secondary flood defences conform the STOWA directive [7], fig. 2.

\subsubsection{Secondary flood defences}

The network of secondary flood defences should have a mix of the following features: hold back floods from flooding further inland, slow down and temporarily reverse floods, divert floods to less sensitive areas, serve as escape routes during a flood and serve as transport routes after a flood.

\subsubsection{Assessment}

To assess whether the network of secondary flood defences can make a positive contribution to flood impact reduction, the province of Zeeland should establish its own standards about required heights and stability of sleeper dikes. An assessment that only can be done experimentally. 
In other words: the province of Zeeland decided to calculate additional flood impact scenarios in order to find, examine and visualize alternatives. The elaborated alternatives will show advantages and disadvantages of possible measures, specified in each diked-area.

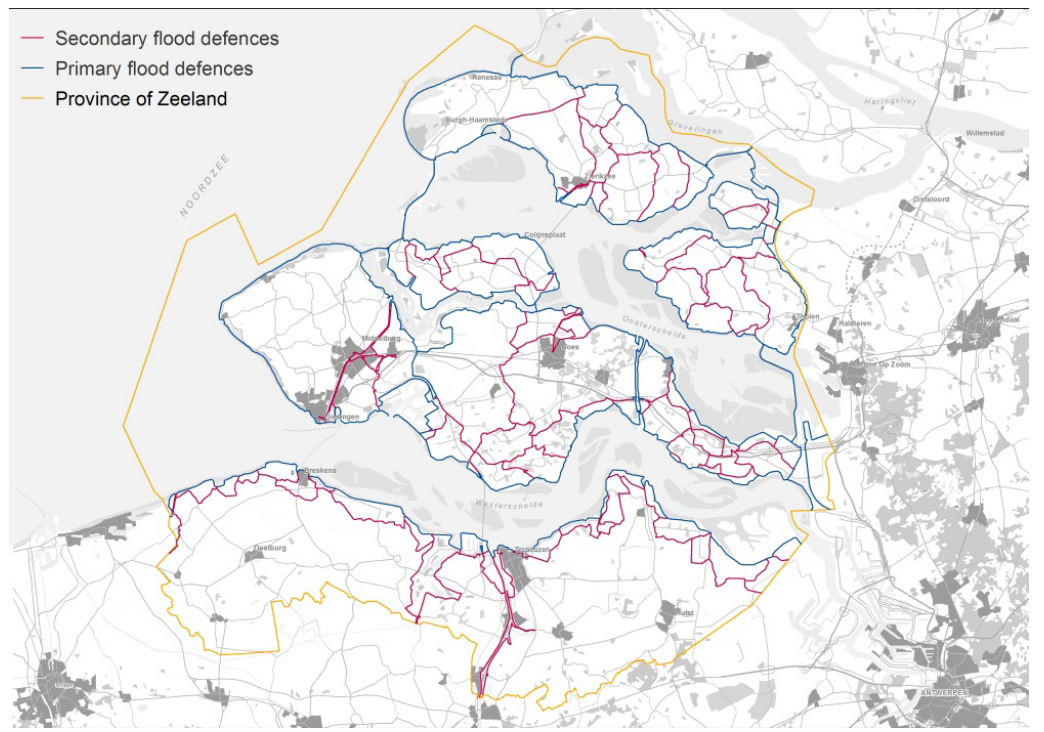

Figure 2: $\quad$ Secondary flood defences.

\subsection{Flood impact calculations}

The province of Zeeland consists of seven diked-areas: six (former) islands and the part bordering to Belgium. For each diked-area recent calculated flood impacts assume all elevated tracks are in the proper (hydraulic) conditions to substantially limit future flood hazards. To get a better impression of what actually happens theoretically, the province of Zeeland visualized the outcome of flood impact calculations in the current situation in stereo 3D, fig. 3.

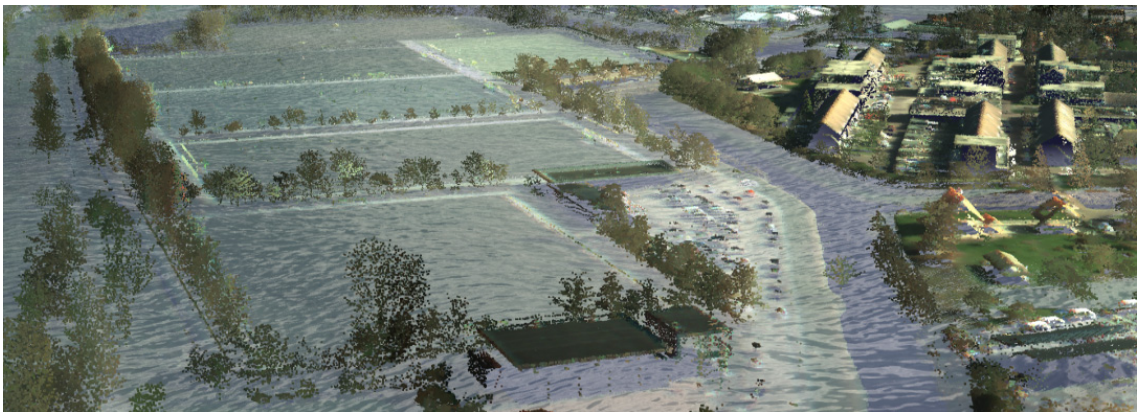

Figure 3: Flood impacts in stereo 3D. 


\subsubsection{The key question}

Studying the stereo 3D visualizations, the first thing to consider is whether these so called "proper conditions" are actually desirable for all our secondary flood defences and other sleeper dikes. Therefore the province of Zeeland decided to adjust recently calculated flood impacts.

\subsubsection{Adjustments}

To demonstrate the desirability of the presence or the absence of sleeper dikes, we have to identify the presumable sensitivity.

The first set of additional flood impact calculations focuses on the network of secondary flood defences. Because reinforcement of sleeper dikes has never occurred, it is not realistic to assume that over a thousand miles of these sleeper dikes will remain standing during a flood. But it is a safe assume that the network of secondary flood defences will. These 380 miles in total are strong enough not to collapse during a flood. The height of this these dikes have been measured in 2012 and will be included in the simulation model. All other sleeper dikes will be erased in the simulation model.

In this case the adjustments will be made in each diked-area. The results will be compared with the current flood impact calculations and prove the value and necessity of the presence or the absence of sleeper dikes without flood defence features. They also tell us in which diked-area the influence of the nation-wide assumption is the most sensitive.

\subsubsection{Promising locations}

The second set of additional flood impact calculations focuses on the promising locations. Area-specific features have to be established. We have to wonder which of the five features of the secondary flood defences, as mentioned in paragraph 2.2.2, is the most important.

This priority ranking cannot be imposed by the government, but must be developed in consultation with all regional stakeholders.

\section{Case study}

Zeeland contains 7 diked areas, each with its own history, dedicated spatial planning and scale. This requires a different policy for each diked area. In order to obtain a kind of similarity, a process approach is necessary.

\subsection{Geodesign}

Geodesign is changing geography by design, a decision driven method designed by [6]. It provides an iterative framework with loops and feedback. There are six questions for each step to answer the following questions: why, how, what, where and when, fig. 4 . This process requires collaboration between the design professionals, geographic sciences, information technologies and the local people. 


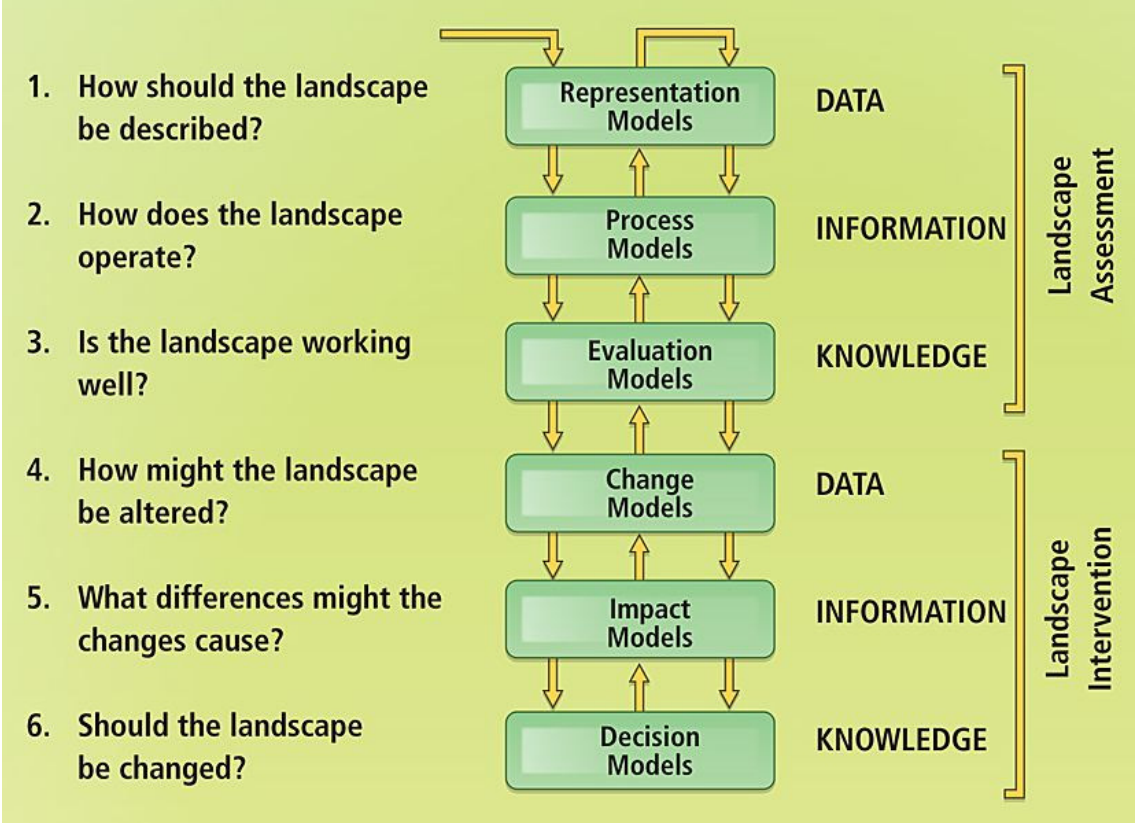

Figure 4: Framework for Geodesign.

\subsection{Why Geodesign}

Due to the vast anthropogenic elements in today's world, it is nearly impossible to neglect any field of activity. Humanity has granted the earth with a very complex layer. An integrated approach is needed to combine design professions and geographic sciences. By applying a method build on collaboration and cooperation it is most likely that insights are included.

"Geodesign lies within the domain of applied science and engineering, seeking ways of addressing practical problems using the scientific method" [8].

The objective is to enable better spatial planning, to improve communication for decision-making and gain experience by conducting case studies.

\subsection{Case studies}

Early 2014 two trial sessions with Geodesign were organized. The first group consisted of students and people of the place, the second consisted of professionals of the province of Zeeland. Both groups were informed on the method and provided with several maps (satellite images, false colour, height, topographic, flood water speed, flood water front), fig. 5. 


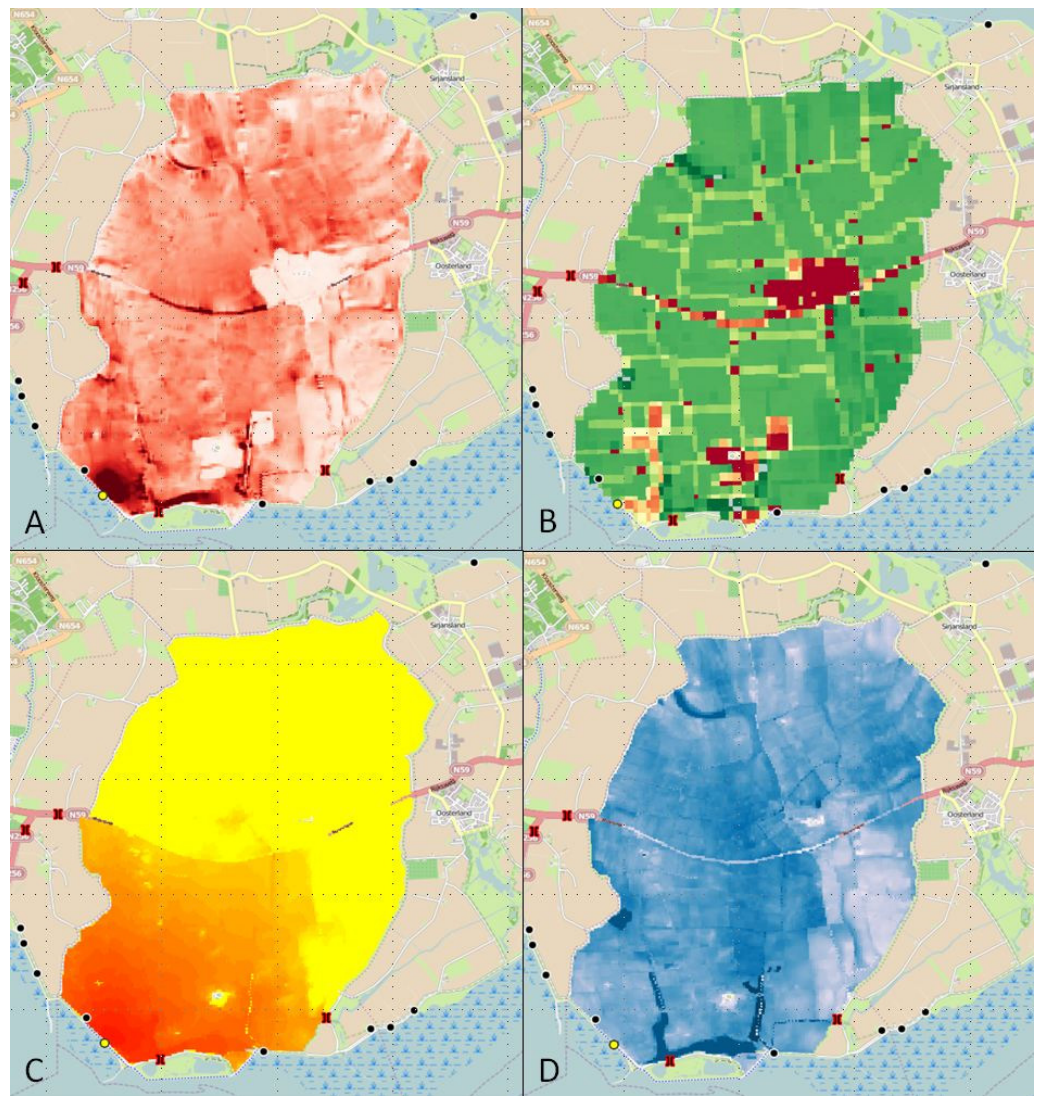

Figure 5: $\mathrm{A}$ - Velocity; $\mathrm{B}$ - damage; $\mathrm{C}$ - arrival; D - max. waterdepth.

\subsection{Results}

Although time was limited some information was missed: information on economy, vital infrastructure, traffic and population numbers. During the trial sessions of the province of Zeeland, both test groups came up with a rather challenging statement: "We actually do have to discourage building in floodprone areas".

\subsection{PhD proposal}

In March 2014 the province of Zeeland joined forces with Associate Professor Dr. Stan Geertman in a PhD proposal "A map-based Planning Support System (PSS) for land and water governance". The overall question of the PhD is: What are the required functionalities of a Planning Support System that supports water managers and spatial planners to make decisions for flood risk management under changing governance conditions. The province of Zeeland will participate in conducting the case studies in Zeeland. 

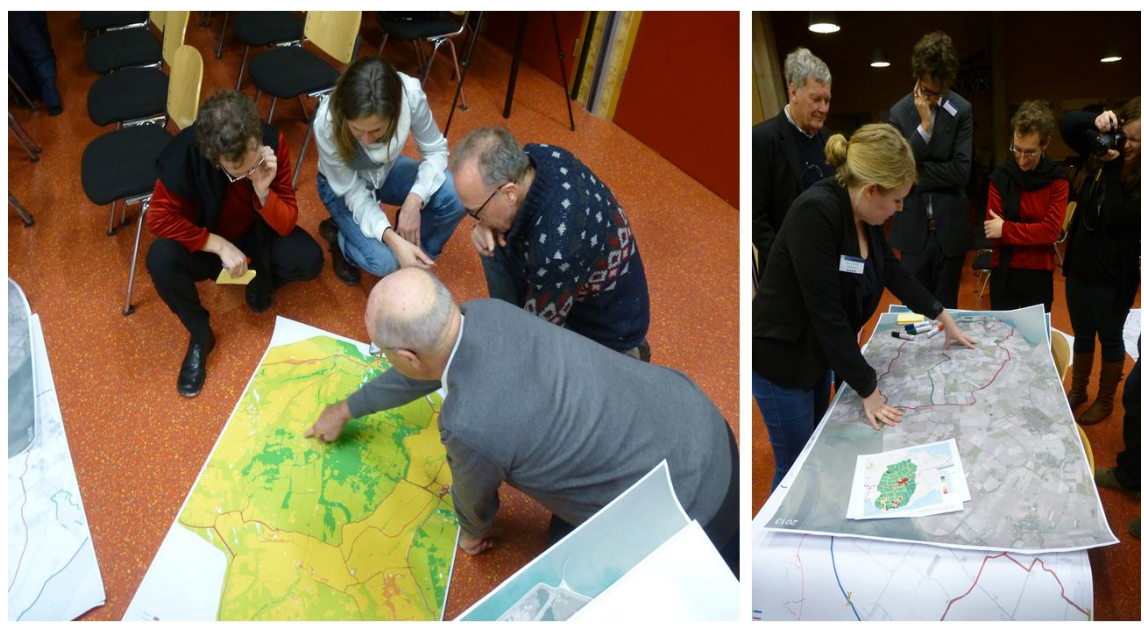

Figure 6: Geodesign in progress.

\section{Conclusion}

During our trial sessions we have learned that Geodesign is an effective method in identifying promising locations in Zeeland for the application of the MLSapproach. To elaborate an integrated regional vision, the province of Zeeland starts using Geodesign in spatial planning to visualize alternatives in flood impact reduction.

\section{References}

[1] Jos Stumpe, Nationaal Waterplan, www.nationaalwaterplan.nl, 22 December 2009, Dutch Government, Thieme Deventer.

[2] Kees Slager, Watersnood, ISBN 978.90.71359.13.2, 2010, Joh. Enschedé, Amsterdam.

[3] Stichting Deltawerken online, www.deltawerken.com

[4] European Commission Directive 2007/60/EC, http://ec.europa.eu/ environment/water/flood_risk/, 26 November 2007.

[5] B. Kolen, M. Zethof, B. Maaskant, Toepassing basisvisie afwegingskader meerlaagse veiligheid; een methode om mee te werken in de praktijk, ISBN 978.90.5773.554.7, 2012, STOWA.

[6] Carl Steinitz, A framework for Geodesign, 2012 CA: ESRI Press.

[7] Chis Geerse, Jan Stijnen, Bas Kolen, Richtlijn normering compartimenteringskeringen, ISBN 978.5773.408.3, December 2007, STOWA.

[8] Michael F. Goodchild, Towards Geodesign: repurposing cartography and GIS? Catrographic Perspectives, number 66, fall 2010, p. 57. 